\title{
CICLOS DE FORMAÇÃO HUMANA NO COLÉGIO ESTADUAL DO CAMPO IRACI SALETE STROZAK
}

\author{
Ana Cristina Hammel ${ }^{1}$ \\ Liliam Faria Porto Borges ${ }^{2}$
}

\section{RESUMO}

Esse trabalho tem como objetivo realizar uma análise crítica do processo de implementação dos Ciclos de Formação Humana no Colégio Estadual do Campo Iraci Salete Strozak e toma por referência a escola presente na atualidade e a necessidade de formação e emancipação dos trabalhadores do campo. A presente pesquisa considerou a implementação dos ciclos como forma de organização do trabalho pedagógico e as bases teóricas que os fundamentam em suas diferentes perspectivas, sobretudo os Ciclos de Formação Humana, opção da escola estudada, tendo como eixo as seguintes questões centrais, emergidas na concreticidade de nossa atuação: quais alterações são possíveis na organização do trabalho pedagógico fundamentado nos Ciclos de Formação Humana, tendo em vista os limites da instituição escolar? De que forma essas alterações se vinculam a uma escolarização que contribua na formação do sujeito social pretendido e anunciado pelo MST? Nesse sentido a pesquisa permitiu entender a dimensão da luta coletiva e a contribuição dos Ciclos de Formação Humana para a formação dos trabalhadores do campo na perspectiva de classe, que contemple uma educação participativa, emancipatória, incorruptível e de qualidade, com protagonistas de novas histórias.

Palavras chave: Educação, Escola, Formação Humana, Ciclos de Formação Humana.

\section{HUMAN FORMATION CYCLES IN THE TATE SCHOOL IRACI SALETE STROZAK}

\begin{abstract}
This paper aims to make a critical analysis from the process of implementation of the Human Formation Cycles in the field state school Iraci Salete Strozak and takes as a reference the school focused in the current moment and the need of formation and emancipation from the field man. This research considered the implementation of cycles as a form of organization from the pedagogical work and the theoretical bases that ground them in its different perspectives, especially the Human Formation Cycles, an option from the school studied, having in its core the following issues, emerged from concrete actions: which changes are possible in the pedagogical work organization in the Human Formation Cycles having in mind the limitation in the schools? In what way these alterations bond in a school formation that contributes to the social individual intended by the MST? This way the research permitted to understand the dimension in the collective fight and the contribution from the Human Formation Cycles to the field men formation in the class perspective, that has a participative, free, incorruptible and high quality education, with protagonists in new histories.
\end{abstract}

Keywords: Education, School, Human Formation, Human Formation Cycles. 


\section{Introdução}

O Colégio Estadual do Campo Iraci Salete Strozak localizado em Rio Bonito do Iguaçu, no assentamento Marcos Freire, centro oeste do Paraná, surge da luta dos Sem Terra e mantém o vínculo com sua pedagogia, expressando a tensão exercida pelo Estado burguês e o direito de optar pelo currículo escolar adequado às demandas dos trabalhadores do campo.

A necessidade de compreender, diante da complexa atualidade dos territórios de Reforma Agrária em seu contexto social e as múltiplas influências que ocorrem sobre a educação escolar, como a escola acumula conhecimento incorporando outra forma organizativa como princípio pedagógico para potencializar a formação dos trabalhadores do campo, construir um novo jeito de fazer e organizar a escola, em meio ao contexto no qual se encontra, foi e é o fator que movimenta a elaboração deste trabalho, ou seja, é necessário buscar compreender de que forma as contradições presentes na sociedade capitalista estão atreladas no processo de organização da escola e as possibilidades que se tem contribuído, ou não, na formação de relações e valores contra a lógica do capital, bem como de aprofundar a compreensão dos elementos educativos que perpassam a forma escolar.

Com esse entendimento, e com vistas às múltiplas determinações do concreto buscou-se responder nesse trabalho até que ponto a organização escolar em ciclos apresenta-se como uma possibilidade de estabelecer parâmetros para superação da ordem vigente? Assim compreender como os Ciclos de Formação Humana (CFH) organizam, por dentro das brechas capitalistas, a formação de sujeitos capazes de lutar por outro modelo social é o desafio dessa pesquisa.

Vale salientar que ao aproximar-se de tais questões assume-se a posição de sujeito desse processo, na condição objetiva da vida cotidiana, na militância e no envolvimento concreto na busca de processos pedagógicos capazes de fazer a diferença na formação de protagonistas de um novo modelo societário, sem necessariamente ser essa uma escolha subjetiva.

O Ciclo de Formação Humana foi a forma que a escola Iraci encontrou para organizar todo esse processo e se contrapor à lógica excludente da sociedade capitalista, para além da superação da escola seriada. Para tanto, toma a realidade vivida e suas relações com a comunidade, com o intuito de construir intervenções político-pedagógicas que possibilitem ao estudante uma nova postura diante do mundo do qual faz parte e de sua história nesse mundo.

Nesse sentido, analisou-se como tem se concretizado os ciclos na escola Iraci, no intuito de trazer à baila os avanços e limites nesse processo e elucidar em que medida a escola se aproxima, ou não, do que anuncia em seu Projeto Político Pedagógico (PPP).

Vale ressaltar que no Brasil, ocorreram distintas experiências de organização de escolas em ciclos, entre elas destacamos, o Regime de Progressão Continuada. Os Ciclos de Aprendizagem e o Ciclo de Formação Humana (CFH).

\section{ORGANIZAÇÃO DA ESCOLA EM CICLOS: PERSPECTIVAS E ABORDAGENS}

A adoção do ciclo segue diferentes concepções e opções ideológicas, assim no decorrer do texto analisamos as características assumidas pela escola Iraci, que na tentativa de organizar seu projeto pedagógico mais próximo do desejado, propõe os Ciclos de Formação Humana ( $\mathrm{CFH})$ como forma escolar, capaz de romper com a estrutura hegemônica seriada. As classes passaram a ser divididas pela idade e não mais pela série, a retenção é substituída pelas Classes Intermediárias, com profissionais para suprir as 
dificuldades dos estudantes e a equipe pedagógica tem a responsabilidade de acompanhar o desenvolvimento do trabalho docente (PPP, 2009).

O Ciclo de Formação Humana (CFH) representa a possibilidade de, no interior da escola, questionar os tempos, espaços e o sistema de avaliação, na medida em que propõe a ampliação do tempo escolar e considera outros espaços educativos para além da sala de aula, redefinindo a avaliação escolar.

Outras formas escolares foram experimentadas no país, entre elas o Regime de Progressão Continuada e os Ciclos de Aprendizagem como estratégias de romper com a reprovação e a linearidade.

A escola organizada em ciclos surge no país como tentativa de resolver os altos custos ocasionados pela reprovação nas décadas de 1910 e 1920, quando autoridades paulistas propuseram a promoção automática nas $1^{\mathrm{a}}$ e $2^{\mathrm{a}}$ séries da escolarização. Associado a isso iniciam nesse período discussões sobre os fundamentos da Escola Nova.

No Brasil, o discurso oficial apegou-se a tais práticas, sobretudo na década de 1950, onde o trabalho docente foi redimensionado visando respeitar as diferenças individuais de cada sujeito, as suas capacidades "naturais". O planejamento deveria ser adequado à fase do desenvolvimento que se encontra os alunos da classe. A aprendizagem é concebida como um ato singular que deve ser facilitada pelo professor, sem que este exija para além daquilo que o aluno possa responder, deve sim, respeitar seu "tempo", pois naturalmente sem intervenção externa, ele construirá a aprendizagem que necessita para viver nessa sociedade.

$\mathrm{Na}$ tentativa de romper com práticas autoritárias, reconhecidas na "pedagogia tradicional" os encaminhamentos pedagógicos devem respeitar os interesses dos sujeitos aprendentes, a comunidade passa a assumir as responsabilidades pelas problemáticas da escola. Assim, a educação assume a função de ajudar no desenvolvimento do potencial individual para tornar o ser humano completo.

É nesse contexto que são organizadas as primeiras experiências de escolas em ciclos, como alternativa para resolver uma séria e profunda crise no sistema educacional brasileiro, superar os graves equívocos provocados pela reprovação e pela organização de turmas homogêneas com tempo linear para todos os estudantes.

Vale lembrar que os ciclos não foram a única proposta apresentada, a própria Escola Nova buscou inovar as práticas consolidadas, mesmo não alterando as relações de poder e por vezes acirrando a exclusão no interior das salas de aulas, o que se convencionou chamar de exclusão por dentro (FREITAS, 2003). Os próprios ciclos cumpriram a função de inclusão, o que não significou necessariamente o rompimento com a lógica estruturada pela escola burguesa, assim explicita que mesmo entre as escolas cicladas há diferenças.

Segundo estudos de Miranda (2009) os ciclos já foram experimentados em países desenvolvidos como Espanha, Bélgica, Canadá, Suíça e a França, cuja justificativa central era assegurar os processos escolares, rompendo com a fragmentação e repeitando os ritmos diferenciados, a fim de superar o "fracasso escolar". Na América Latina, além do Brasil, a Argentina implanta os ciclos em 1993 (MAINARDES, 2009/201).

$\mathrm{Na}$ França, as noções da organização escolar em ciclos derivam do Plano de Metas Langevin-Wallon elaborado entre os anos de 1946 e 1947 na França (MAINARDES, 2009/2011). Entre as metas prevista no plano, Mainardes (2011, p. 30) destaca:

a) igualdade e diversidade, significando que todas as crianças, independentemente, de suas origens familiares, sociais, étnicas, têm igual direito do desenvolvimento máximo das características de sua 
personalidade; b) reconhecimento de igual dignidade para todas as funções sociais, não menosprezando as habilidades de trabalho manual ou inteligência prática em relação a outras habilidades; c) em uma democracia devem-se proclamar e proteger os direitos dos mais fracos e de todos à Educação, garantindo o desenvolvimento pleno das habilidades individuais; d) valorização de uma cultura geral, para que a especialização técnica não limite a compreensão dos problemas mais amplos, ou seja, a formação do trabalhador não deve prejudicar a formação do homem, e sim caracterizar-se como uma formação complementar para um amplo desenvolvimento humano.

Diante dos pré-requisitos apresentados para alteração do sistema escolar na França e de forma geral, pelas escolas que passaram a se organizar em ciclos, reconhece-se a tentativa de tornar a escola democrática, inclusiva e que respeite a diversidade, ao mesmo tempo em que se garante a igualdade que todos têm direito.

À "lógica dos ciclos" (FREITAS, 2003) mexe na estrutura escolar centrada na seriação, ou na educação consolidada na sociedade burguesa, o que à primeira vista podem parecer práticas restritas às capacidades ou habilidades individuais. No entanto, podem significar a diferença entre a lógica da exclusão/ submissão e a da emancipação humana. Isso exige das redes mudanças significativas desde a estrutura física dos prédios escolares até a formação e remuneração dos docentes, as concepções, práticas e os registros do desenvolvimento e da aprendizagem.

A escola proposta por Wallon e Langevin incluía um conjunto de mudanças como a organização das turmas de forma a diminuir o número de estudantes por turma, estes com bolsa auxílio, aumento de professores na mesma, escolarização obrigatória até os 18 anos entre outras mudanças. (MAINARDES, 2011).

No Brasil a primeira experiência de escola em ciclos foi na década de 1980 em São Paulo, muito embora esse termo já apareça durante a Reforma de 1930, associado às políticas de não reprovação (MAINARDES, 2009).

Conforme Mainardes (2001), nesse contexto em que grupos políticos e educadores progressistas passam a assumir cargos importantes nas instâncias mediadoras, medidas inovadoras são implantadas na escola pública, entre elas, o Ciclo Básico de Alfabetização. Esse processo só é legitimado pela Lei de Diretrizes e Base da Educação Nacional (9394/96) em 1996, que reconhece no artigo de $n^{\circ} 23$ os ciclos como forma de organização escolar. Diz o texto, "a educação básica poderá organizar-se em séries anuais, períodos semestrais, ciclos, alternância regular de períodos de estudos, grupos não-seriados, com base na idade, na competência e em outros critérios" (LDB, 1996).

Cunha $(2012$, p.7) apresenta os ciclos como opção das reformas educacionais no país e como uma orientação presente nos Parâmetros Curriculares Nacionais (PCNs) de 1997, segundo ele: "os PCNs trazem orientações gerais para o processo de ensinoaprendizagem no ensino fundamental, ratificam que essa estrutura (ciclada) possibilita trabalhar melhor com as diferenças e está coerente com os fundamentos psicopedagógicos".

Teixeira (2008) em sua pesquisa chama atenção para associação entre a adoção dos ciclos a diferentes motivadores, que geram práticas diferenciadas que vão desde as aproximações às propostas progressistas ao neoliberalismo, dependendo da postura política assumida.

Os Ciclos vêm apresentando possibilidades de debater além da lógica linear e devem ser compreendidos como articuladores do dinâmico e complexo processo de desenvolvimento e de aprendizagem dos sujeitos. Não podem apenas legitimar a mudança 
da realidade formal escolar, mas também oferecer a possibilidade de superá-la em todas as suas configurações de ensino conhecidas, como, por exemplo, o próprio processo de avaliação que é previsto nas desigualdades do desenvolvimento e da aprendizagem entre os sujeitos.

Esse novo modo de pensar exige definição de princípios, metas, conhecimentos próprios, de acordo com as idades, principalmente aos grupos de idade-ciclo. Se estivermos numa lógica de seriação podemos enquadrar o processo de ensino em sequências anuais, semestrais ou ainda, bimestrais, com conteúdos e tempos graduados. Contrariamente ao que ocorre nos Ciclos, os tempos têm outra dinâmica, mais extensa e ressignificada a partir das temporalidades ou da condição humana do interagir sócioantropológico (os tempos da vida). Os ciclos da vida são processuais, pois não cessam na prescrição ou no conceito final sobre as vivências conquistadas.

Assim, na escola do ciclo, o tempo de aprendizagem é o tempo do desenvolvimento da vida humana, que passa por diferentes ciclos (infância, adolescência, juventude, adulto e velhice). Compreender como se aprende em cada ciclo da vida passa a ser pré requisto para trabalhar os conteúdos escolares.

Os ciclos mexem nessa lógica e propõem métodos de ensino que dialoguem com a vida real e com a totalidade. Para Miranda (2005, p.642) na escola dos ciclos o importante é o sujeito estar na escola, pois estará aprendendo algo, sendo este espaço fundamental para a "experiência da cidadania, da convivência e da formação dos valores sociais". Embora essa afirmação seja importante, os estudantes precisam mais que permanecer na escola, ela deve ser espaço de conhecimento para que as novas gerações possam aprender o que essa sociedade já construiu e que cada indivíduo se desenvolva enquanto ser humano, em um processo responsável e saudável, sem para isso precisar subjugar outro ser ou espécie viva.

Portanto essa escola precisa ser mais que apenas espaço de convivência e de aprendizado de valores, os estudantes precisam ter acesso ao que de melhor a humanidade construiu. Questionar e se posicionar sobre cada instrumento, cada valor, sobre as formas de trabalho e os valores capitalistas, experimentar outras formas organizativas de poder, participar das decisões, assumir as consequências por seus atos, é assim que se colabora para formação de seres humanos capazes de construir a sociedade socialista.

Entre os argumentos e críticas apresentados à escola ciclada destacamos as disputas no interior de cada prática e o jogo de interesses que se expressa nas ideologias e no projeto societário a que se vinculam. Muito embora algumas mudanças se deem apenas no âmbito formal, não representando de fato alterações profundas no sistema educacional, Alavarse (2009) destaca que mesmo sem "um modelo" os ciclos instauram uma tensão na estrutura hegemônica.

Nesse cenário onde se materializam disputas e controvérsias os ciclos vêm configurando a luta pela defesa de que todos têm direito a estudar. Para isso a escola precisa ser lugar de aprendizagem e se organizar, com tempos, espaços e pessoas preparadas para isso.

A adoção dos ciclos exige uma mudança significativa nas concepções que sustentam as práticas pedagógicas e sua consolidação. Se representarem apenas uma mudança na forma e não no conteúdo será uma mudança inócua. (PPP, 2009). Entendemos então que há na organização escolar em ciclos, elementos que possibilitam discutir formação e emancipação humana, desde a escola, para isso precisamos entender que mudanças são necessárias para superar as desigualdades, sem idealizações e sem frustrações, pois cada passo na construção do novo agrega para haver possibilidades de chegarmos à sociedade socialista. 
Uma observação mais atenta revela que algumas características marcaram as diferentes perspectivas dos ciclos, o que difere radicalmente são as relações estabelecidas nos contextos locais onde a experiência é concretizada, no caso da escola Iraci, o vínculo com o MST. Assim nossa intenção é investigar como essa aproximação qualifica ou não o trabalho pedagógico.

Os Ciclos de Formação Humana foram implantados na escola Iraci em decorrência da demanda de formação de sujeitos que pudessem contribuir na transformação social, pautada na exploração humana.

Embora ambos os pressupostos, tanto dos $\mathrm{CFH}$, quanto da Pedagogia do Movimento (MST) estejam diretamente vinculados a um discurso progressista, procuramos as contradições que trazem as marcas da socialibilidade às quais são submetidas, ou seja, a sociedade capitalista.

Como expressa o título: 'Ciclos de Formação Humana no Colégio Estadual do Campo Iraci Salete Strozak', o texto que apresentamos é o resultado da análise dessa experiência educativa, que ao optar pelos ciclos buscou romper com a lógica educativa hegemônica.

Compreender porque o Ciclo de Formação Humana é escolhido como instrumento para consolidar o projeto pedagógico na escola estudada, ajuda a entender a perspectiva política de formação dos estudantes nesse espaço, os quais trazem como perspectivas anteriores a ocupação da terra e a luta pelo acesso a direitos sociais, constituídos no seio da própria sociedade capitalista. Saes (1998) explicita que ao lutar/acessar alguns direitos civis e o direito à organização, os trabalhadores precisam apropriar-se destes mecanismos para formar consciências e construir bases para o socialismo.

Para sustentar o trabalho e contribuir no campo do conhecimento social, a partir do tensionamento do campo de pesquisa e em meio às atividades desenvolvidas na escola desde 2003, a pesquisa participante foi a metodologia empregada no desenvolvimento do trabalho.

Assim foram observadas as práticas dos sujeitos envolvidos no processo: professores, pais, educandos e gestão escolar, com o intuito de entender como elas avançam no sentido de construir uma educação, que se coloca contra a "internalização" da “incorrigível lógica do capital” (MÉSZÁROS, 2005).

Em termos de procedimentos metodológicos, as experiências anotadas no Caderno de Campo, construídos ao longo de oito anos de luta pela implantação da proposta; as memórias e as falas das pessoas que, de alguma forma, fizeram e fazem parte da história dessa escola foram consideradas. Amplamente utilizado esse instrumento sistematizou estudos, debates, os fatos considerados significativos, as impressões do processo, o que ora nos ajuda na reflexão da práxis.

Foi realizado estudo bibliográfico sobre as diferentes experiências de organização em ciclos no país a partir das sistematizações de autores como Freitas (2003), Mainardes (2007, 2009), Krug (2006), entre outros.

Os PPPs da escola Iraci (2000 e 2009) e os documentos do MST sobre a Pedagogia do Movimento foram bibliografias importantes na análise, bem como sua materialização na prática pedagógica. Como aporte teórico, Vigotsky (2000; 2005) e Leontiev (1978), são referenciais que fundamentam o projeto educativo da escola pesquisada, sobretudo subsidiam as concepções acerca da aprendizagem e do desenvolvimento humano, portanto apreciados no decorrer do trabalho.

Dedicamos-nos a entender os ciclos na escola Iraci, desde as categorias fundantes no trabalho pedagógico da escola, a compreensão acerca da educação, escola, ensino, conhecimento, formação humana, desenvolvimento e aprendizagem, bem como o tempo 
escolar e a avaliação no interior da prática pedagógica. As práticas e o desenrolar dos processos e contradições internas e externas, os avanços e limites desde as experiências e intenções anunciadas no projeto educativo na escola. O exercício de análise prosseguiu na direção de elencar o diferencial formativo possibilitado pelo vínculo orgânico entre a escola Iraci e a luta do MST, e como a escolha pela organização escolar nos Ciclos de Formação Humana se torna um diferencial ou não nessa opção.

\section{A ESCOLA EM CICLOS: CATEGORIAS DE ANÁLISE}

Para efetuar análises críticas procuramos definir e conceituar categorias importantes para compreender a experiência vivida no colégio estadual do campo Iraci Salete Strozak (escola Iraci) na organização do fazer pedagógico em Ciclos de Formação Humana. Segundo Martins (2009) as categorias são essenciais para a compreensão dos fenômenos e seus nexos com a totalidade entendida como um conjunto de ações desenvolvidas a partir de um Projeto Político Pedagógico (PPP) o qual busca uma prática educativa vinculada à emancipação humana. A opção foi perceber como as categorias centrais para o desenvolvimento humano se articulam ao projeto educativo expresso no PPP (2009) da escola.

O ponto de partida foi a retomada de elementos chaves que estão articulados e que em determinados modelos escolares, assumem concepções diversas. Neste âmbito, para avançar no processo de compreensão da formação proporcionada na escola Iraci, recuperaremos conceitualmente as categorias de educação, escola, ensino, conhecimento; formação humana, desenvolvimento e aprendizagem; tempo, avaliação e promoção. Partimos do princípio que em determinadas situações, estas categorias assumem diferentes conceituações, e mesmo na práxis pedagógica, podem ser resignificadas pelos sujeitos no processo.

Logo nos primeiros parágrafos do PPP (2009) da escola Iraci, há uma diferença significativa das demais escolas paranaenses: a opção do trabalho pedagógico organizado em Ciclos de Formação Humana, e também, a formação onmilateral, a formação para a cooperação e a solidariedade entre outros valores que pretendemos analisar com maior profundidade no decorrer desse trabalho. Para o coletivo da escola a organização do ensino e da educação escolar atual não contribui para a formação do sujeito necessário a sociedade socialista almejada pelos trabalhadores militantes, pois está intimamente vinculada a hegemonia do capital, onde não há espaço para a classe trabalhadora.

\subsection{A Formação Humana e a centralidade do Trabalho Pedagógico.}

A escola é o espaço consolidado para a transmissão formal da cultura e da história construída pela humanidade, com adultos responsáveis, por garantir o desenvolvimento humano (DUARTE, 2000, p. 83). Porém, numa sociedade que os seres humanos são dispensados qual seria o papel da escola? Qual é o entendimento de desenvolvimento humano se a própria humanidade está em risco?

Não sendo a escola um local neutro, estando à mercê de determinações do sistema social em que se insere, ela é também capaz de produzir alterações nesse sistema. Reconhecer a importância que a escola assume na modernidade, é compreender em que aspectos ela contribui para a luta e emancipação dos trabalhadores.

$\mathrm{Na}$ escola Iraci, o ensino abrange a transformação dos conceitos cotidianos em científicos (PPP 2009, p. 33), pois o conhecimento escolar deve ser capaz de produzir sínteses elaboradas, o que sugere reconhecer cada elemento em sua complexidade, e em sua forma mais acabada. Isto é possível com um método e uma metodologia que não 
apenas repita o que já é conhecido, mas também, e, sobretudo, oportunize conhecer aquilo que não se sabe, e que seja indispensável para o desenvolvimento da humanidade.

$\mathrm{Na}$ situação analisada, a escola pelo menos em termos formais, anuncia um conhecimento que corresponda "a formação integral dos povos do campo" (PPP, 2009, p. 26). Sabedores de que há diferentes entendimentos do que seja formação integral, a compreensão incorpora a formação de personalidade, além dos conteúdos formais definidos no currículo. Assim, cumpre a escola a função de atualizar o ser em sua humanidade, mais também desenvolvê-lo em seu potencial cognitivo e criativo.

Assim, definição da Escola Iraci sobre desenvolvimento humano não foge à compreensão do descrito até aqui, concebe-o associado ao papel que cada sujeito assume no processo de produção da vida e nas experiências que vai experimentando ao longo da história.

o educando não começa a aprender e se desenvolver na escola. Quando ele chega até ela, já aprendeu várias coisas e já se desenvolveu parcialmente. Nosso papel é valorizar o processo que já realizou e contribuir para ampliar tanto a aprendizagem como o desenvolvimento (PPP, 2009, p. 33).

Retomando o PPP (2009) da escola Iraci, fazemos alusão aos estudos de Vygotsky, verificamos que a escola concebe aprendizagem e desenvolvimento como processos que se complementam e se completam. Outro elemento importante é a identificação que ambos não ocorrem apenas em seu interior, como já dissemos, esses são anteriores à própria organização escolar. Porém a aprendizagem escolar dá um novo rumo ao desenvolvimento, sobretudo ao da criança que ao aprender, constitui estruturas no intelecto que são usadas em operações gerais e específicas.

Para Vygotsky (2005) o intelecto não é a mera reunião de capacidades especificas, ou seja, memória, atenção, juízo, observação, o intelecto compõem-se dessas e de outras capacidades, por isso, os docentes precisam trabalhar não no sentido de desenvolver características especificas, mas o todo, o intelecto. Para auxiliar na atuação didática, o autor identifica duas formas de desenvolvimentos e estabelece como deve proceder o ensino para que de fato a criança aprenda e se desenvolva. Nas palavras do autor:

Tem de determinar pelo menos dois níveis de desenvolvimento de uma criança, já que, senão, não se conseguirá encontrar a relação entre desenvolvimento e capacidade potencial de aprendizagem em caso específico. Ao primeiro destes níveis chamamos nível do desenvolvimento efetivo da criança. Entendemos por isso o nível das funções psicointelectuais da criança que se conseguiu como resultado de um específico processo de desenvolvimento, já realizado. [...] A diferença entre nível das tarefas realizáveis com a ajuda dos adultos e o nível das tarefas que podem desenvolver-se com uma atividade independente define a área de desenvolvimento potencial de uma criança. (VYGOTSKY, 2005, p. 13). ${ }^{3}$

As indicações do autor fornecem elementos para organização do ensino e instrumentaliza os docentes em uma perspectiva que avança no sentido da tomada de decisão, uma vez que, o desenvolvimento e a aprendizagem emergem para além de fatores biológicos. A formação de fatores psicointelectuais superiores, que caracterizam a existência humana, aparecem no decurso do desenvolvimento. Primeiramente na atividade 
social, coletiva, só então se internaliza no pensamento e assume características individuais. A linguagem, como uma construção social, cumpre a função de verificação do próprio pensamento e internalizado pela mesma linguagem. A escola que se vincula a esta concepção, busca potencializar as capacidades humanas e opta pela dinâmica que contribui para o desenvolvimento de estruturas superiores, não se apegando a mera reprodução e verificação de processos inferiores.

No PPP da escola Iraci, é possível verificar como ele se aproxima das teorias explicitadas acima.

Podemos compreender de uma forma diferente: que o que o ser humano traz ao nascer, ou seja, suas características biológicas não são suficientes para sobreviver e se desenvolver. Os fatores biológicos preponderam sobre os sociais apenas no início da vida. As relações que o ser humano vai estabelecendo durante a sua vida têm uma influência importante no seu desenvolvimento. $\mathrm{O}$ trabalho é a relação de um ser humano com outro ser humano e com a natureza. Nesse processo ele modifica o outro, modifica a natureza e é modificado, ou seja, ao interagirmos com os outros vamos modificando os outros e vamos sendo modificados. Isso também significa dizer que o ser humano é histórico-social, vai se constituindo numa história, na história das relações que estabelece. (PPP, 2009, p.32).

Neste sentido, o próprio entendimento do que seja conhecimento ultrapassa a mera representação ou apreensão da realidade no pensamento. Conhecimento compreende, como se refere Prado Junior (2001, p. 34), a apreensão das relações que compõem cada fração da realidade, "trata de descobrir, determinar e representar mentalmente. E são as representações assim formadas e elaboradas que precisamente constituem o que entendemos por Conhecimento".

Apoiado na construção de Marx (1857), o autor explicita a formação do conhecimento como um processo de elaboração desde o concreto (fato real) à passagem para o conceito (fato mental) envolvendo representações intelectuais, a partir da percepção e da intuição. Sendo assim "a totalidade, que se manifesta no espírito como um todo pensado, é um produto do cérebro pensante que se apropria do mundo pela única forma possível" (PRADO JUNIOR, 2001, p. 37).

Dessa forma, entendemos que o processo de conhecer e o próprio conhecimento envolvem elaborações mentais de relações complexas, partimos do conhecimento prévio da realidade (ou de uma porção), o qual será confrontado e produzirão novas sínteses, ou conhecimento novo. Cada sujeito precisa passar por este processo, apreender o concreto e a construir conceitos para entender a constituição do real em sua essência.

Se pretendemos um método que de fato desenvolva as estruturas mentais e as plenas capacidades humanas, a escola e o ensino em seu interior precisam ensinar a construir conceitos. Esta capacidade ninguém transfere, pois é um processo individual que se aprende assim como a viver na coletividade, o respeito ao outro e a solidariedade, entre outros valores fundamentais para a construção de uma nova sociedade.

Kostiuk (2005, p. 31) alerta para a capacidade da ação educativa sobre a formação do ser humano. Ao oportunizar o conhecimento, influenciamos em sua experiência social capacitando-o a desenvolver atitudes, como o gosto pelo trabalho, por exemplo. Segundo o autor, isto ocorre "sob a influência de determinadas exigências sociais externas aceitas e assimiladas, que depois se transformam em exigências internas que o mesmo aluno faz". 
Esses resultados não são assimilados de forma tranquila e de maneira igual, cada sujeito social reage de modo diferente, dependendo de sua situação subjetiva, do contexto vivido e de como a atividade vai ou não, responder a situação real, ou seja, ao interesse real. Isso não significa, entretanto, que o aprendizado deve ser aquele que apenas responde a necessidade a priori, esta realidade deve fornecer elementos para subsidiar a elaboração dos planos de ensino pelos docentes, adultos que irão fazer a intervenção.

Faz-se necessário, assim retomarmos ao que entendemos por realidade e totalidade, ambas são perenes no PPP (2009) da escola Iraci. A preocupação com os saberes e as vivências são fenômenos que contribuem, segundo o PPP (2009, p. 30), para a humanização. Segue parte do texto original:

O ser humano se educa manuseando as ferramentas que a humanidade produziu ao longo dos anos. É a cultura material que simboliza a vida. O ser humano também se educa com as relações, com o diálogo que é mais do que simples troca de palavras. Ele aprende com o exemplo, aprende fazer e aprende a ser olhando como os outros fazem e o jeito como os outros são. Os educandos olham especialmente para os educadores que são sua referência como modo de vida.

O desafio parece aqui, entender como o micro apresenta elementos da totalidade. "O particular e local precisam ser entendidos como a expressão do geral". (KLEIN, 2002, p. 52).

Freitas (2003, p. 57) ao considerar a realidade como instrumento necessário ao ensino, busca romper com a lógica escolanovista. Apoiado em estudos de pedagogos e teóricos russos, o autor resalta que "é importante para contrapormo-nos ao "escolanovismo" latente em nossa formação pedagógica ocidental. Há o lado psicológico do desenvolvimento, mas há também o lado social da formação". Nessa perspectiva o autor traz do contexto social a ser considerado na formação dos estudantes,

deve-se se entender por formar na atualidade tudo aquilo que na vida da
sociedade do nosso tempo tem requisitos para crescer e desenvolver-se
que em nosso caso tem a ver com as grandes contradições da própria
sociedade capitalista. A formação do aluno, portanto deve prepará-lo para
entender seu tempo e engaja-lo na resolução dessas contradições, de
forma que sua superação signifique um avanço para as classes menos
privilegiadas e um acúmulo gradual e permanente de forças para a
superação da própria sociedade capitalista. (Freitas, 2003, p.56)

Não é preciso uma análise mais apurada para perceber que os autores, que trouxemos até agora, têm em comum o compromisso de uma escola que contribua com os trabalhadores, tal como anuncia a escola Iraci nesta busca por vários caminhos que têm sido percorridos. Tal como Freitas (2003) alerta para necessidade de superarmos a escola feita para os "pobres", e reconhecermos a existência de uma escola pensada estrategicamente para uma classe.

Na mesma perspectiva Duarte (2001) discute a necessidade dos trabalhadores acessem o conhecimento, uma vez que na sociedade do consumo este bem pode ser acessado apenas no limite que responda aos interesses da burguesia. Nas palavras de Duarte (2001, p. 26). 
A estratégia de luta daqueles que estejam comprometidos com a superação de sociedade capitalista deve ser a de agudizar as contradições dessa sociedade, na direção de uma efetiva socialização dos meios de produção. No caso da educação escolar, trata-se de resistir a todas as artimanhas da ideologia dominante, que resultam em processos objetivos pelos quais a sociedade contemporânea lança as massas não só na miséria material mas também na miséria intelectual.

Como já afirmamos anteriormente, a escolha feita pela escola estudada para organizar um ensino que seja capaz de romper com a lógica capitalista para a educação escolar, foi a opção pelos Ciclos de Formação Humana.

\subsection{A organização escolar e a consolidação das categorias no processo de formação humana: o tempo escolar e os mecanismos avaliativos.}

\subsubsection{O Tempo Escolar.}

Ao pensar a organização da escola na sociedade capitalista, recriar suas raízes dentre tantos elementos apontados até aqui e outros tantos secundarizados neste texto, como elemento fundante da escola em ciclos, trataremos sobre o tempo.

Segundo Claudia Parente (2010, p. 136) os tempos escolares "fazem referência ao início e à duração da escolarização (tempos de escola); à organização da escolarização (tempos de escolarização); às construções consolidadas no interior das instituições escolares (tempos na escola)".

Não apenas no que tange o ambiente escolar, o tempo assume no capitalismo um fator predominante. O tempo do trabalho e o salário pago ao trabalhador irá determinar o lucro do patrão. Nessa complexa relação entre tempo, trabalho e lucro, o próprio tempo vira uma mercadoria, tendo influência direta no valor final do produto. Marx escreveu em O Capital "[...] O que determina exclusivamente a magnitude do valor de qualquer produto é, portanto, a quantidade de trabalho socialmente necessário à produção (I, cap. I)". E assim, entre as formas de medir o trabalho no capitalismo está o tempo dedicado a ele.

O tempo escolar precisa ser analisado nesse contexto, pois não se desvincula do projeto de sociedade, sendo ele uma construção humana envolto na complexidade social, portanto histórico, constitui-se em uma categoria fundamental na relação ensinoaprendizagem e desenvolvimento humano. escolar,

Parente (2010, p. 137) reafirma essa premissa quando escreve sobre o tempo

A categoria tempo é aqui definida como conceito histórico, social e cultural. Aceitar essa premissa significa aceitar que a noção de tempo não é elemento a priori, ou seja, que existe assim como os diversos elementos da natureza. Significa ainda aceitar que a noção de tempo é elemento da criação humana e tem passado por inúmeras transformações ao longo da história.

Na Idade Moderna o tempo escolar é resignificado e pensado com determinantes específico do modo de produção vigente. A necessidade de formação de um novo sujeito social, o operário que substitui o servo nos novos postos de trabalho, suscita para a escola essa tarefa, que passa por questões fundamentais como o controle da infância e da juventude, a fim de modelar o adulto necessário à fábrica moderna. 
Diante desta necessidade, a escola é democratizada e possibilita a um grande número de estudantes o acesso ao conhecimento necessário à nova organização social (ideologia dominante), que precisa ser consolidada no menor tempo possível.

Freitas (2003) em suas análises sobre o tempo, nesse modelo escolar, identifica como é utilizado para práticas de submissão nas vivências dos estudantes. Além da execução de tarefas que treinam e moldam os corpos e comportamentos, os estudantes precisam respeitar/obedecer às normas para não "repetir o tempo" na mesma série. Assim se estabelecem por meio de horários: o "tempo ocupado e tempo livre, tempo de aprender e tempo de brincar, tempo de atividade e tempo de ócio, tempo de silêncio e tempo de falar, os horários consubstanciavam ainda a fragmentação do saber" (SOUZA, 1999, p. 134).

No PPP (2009) da escola Iraci, o tempo é resignificado desde os Ciclos de Formação Humana. Entre as considerações que apontamos brevemente nesse momento, está o alargamento do tempo. Cada ciclo de escolarização compreende três anos, respeitando o ciclo da vida em que o sujeito se encontra, ou seja, infância, préadolescência, adolescência, juventude, adulto e velhice.

A escola estudada considera que a construção de um projeto de ensino vinculado e comprometido com a classe trabalhadora, passa pela reestruturação do tempo escolar, porém não basta alterar o tempo se não houver a compreensão de como o sujeito se constitui, desenvolve e aprende, o que implica em compreender como a sociedade se organiza e esta organização se expressa num fato histórico-social, numa realidade material contraditória e dialética. Assim podemos ler no PPP (2009, p. 31) da escola Iraci.

Entendemos, então que organizar a escola em Ciclos de Formação Humana significa romper com a fragmentação do saber e alargar os tempos de aprendizagem e desenvolvimento, possibilitando a convivência com a diversidade. Assim sendo, faz-se necessário refletirmos sobre nossa concepção de ser humano, sociedade, desenvolvimento e aprendizagem. [...] Não quaisquer mudanças, mas aquelas que contribuam para a emancipação humana, para a superação da desigualdade. Se acreditamos nisso é porque compreendemos que as coisas não estão prontas e acabadas, mas sim em permanente construção. Essa forma de ver a sociedade exige uma forma diferente de ver o ser humano.

Essas caracterizações trazidas até aqui, são amplas, porém nada vagas pois são carregadas de contradições e possibilidades. Prova disso é que ao se respeitar os tempos e espaços e os comportamentos individuais, não podemos recusar ou desrespeitar a condição humana, aquilo que nos separa do que é natural, ou seja, a capacidade de superar a própria natureza. Portanto, como aponta Klein (2002), há que se ter cuidado quando se fala em respeitar os ritmos de aprendizagem de cada pessoa, pois isto pode significar o não desenvolvimento do ser humano.

\subsubsection{Os mecanismos avaliativos.}

Associada a lógica do tempo escolar soma-se a exclusão promovida nos processos avaliativos. Ao adentrar nas questões da avaliação escolar, não podemos desassociá-la do tempo e da "lógica escolar" (FREITAS, 2003),

Freitas (2003) valendo-se das análises feitas à escola consolidada no capitalismo, identifica como ela criou mecanismo artificiais de verificação do processo escolar, chama a atenção para a necessidade de atribuir uma nota ao final do processo. Ao estabelecer a 
"nota" nivelam-se os graus de aprendizagem, aprender passa a ser atingir a média e os que não a atingem são conduzidos a repetir até alcançarem o índice estabelecido.

A artificialização que atinge a escola é resultado, segundo o autor, da separação entre ensino e vida. A escola, neste caso, é o ambiente criado para que as contradições fiquem do lado de fora, ou ainda, as que adentram esse espaço são justificadas pela autoridade docente e/ou da gestão escolar, e a própria avaliação nesse espaço passa a ser motivador artificial.

Em seu trabalho o autor descreve a existência de três componentes dentro do sistema avaliativo das escolas "tradicionais", recuperamos rapidamente, cada um deles, para entender a lógica assumida na escola Iraci. Para Freitas (2003) a avaliação ocorre em três níveis complementares e associados. O primeiro ele chama de aspectos instrucionais, os quais abrangem a verificação dos conteúdos e conhecimentos ensinados durante o tempo da aula, são as provas, trabalhos e outros instrumentos utilizados pelos professores como recursos para a verificação da aprendizagem.

O segundo, intitulado aspecto comportamental, incide sobre o controle estabelecido no interior dos ambientes escolares, a obediência pelos estudantes às normas, às regras, isso tem estruturado uma relação de poder que, nas análises do autor, interfere nos resultados cognitivos do alunado, uma vez que o docente estabelece um pré-conceito e busca confirmá-lo ao aplicar os instrumentos avaliativos. Associado a mesma lógica está o terceiro aspecto, a avaliação de valores e atitudes, que consiste em expor o estudante à submissão, por meio de represálias e repreensões impondo uma autoridade que, por ora, é do docente e depois, do patrão.

Nesse sentido Freitas (2003) traz à tona dois planos em que ocorre a avaliação escolar, "um formal e outro informal", e em muitos casos, o plano informal acaba incidindo inclusive sobre os instrumentos "formais" criados pela própria escola. Os juízos de valores ou os pré-conceitos determinam, não apenas o padrão social, mas também qual o lugar de cada um nessa sociedade.

No ínterim dessas determinações, o plano informal cumpre um procedimento indispensável na função social que essa forma escolar, assume na atualidade. Nas palavras do próprio Freitas (2010, p. 91) "a subordinação é uma das funções sociais que a escola tem para adequar os estudantes ao poder escolar, na forma como ele se institui na escola atual".

Acrescenta ainda, "a forma escola despersonalizou o trabalho escolar e sujeitou tanto professores (agora como funcionários do Estado) e os estudantes a uma lógica impessoal que está acima deles (regras) - entre as quais a avaliação" (FREITAS, 2003, p. 91).

Tentativas para superar a lógica excludente da avaliação escolar, passam a ser experimentada a fim de atingir uma pretensa inclusão e um melhora significativa nos baixos índices de aproveitamento escolares. A avaliação passa a ser formativa, somativa e diagnóstica; o erro passa a ser considerado processo e o professorado deve considerar os ensaios de seus alunos na aprendizagem.

Em que pesem a importância das mudanças assumidas nas perspectivas descritas acima, concordamos com Freitas (2010) quando considera que tais mudanças não resultam na alteração das práticas no interior da escola uma vez que a raiz da questão não está na metodologia, mas no próprio decurso da ação, ou seja, uma prática revolucionária exige uma escola revolucionária.

Assim, é necessário ir além de uma mera inversão da ordem ou da criação de elementos artificiais, ou seja, é preciso recuperar instrumentos que tornem o homem humano. Isso implica em admitir que a humanidade só é possível em meio a uma 
intervenção qualificada do adulto já humanizado. Negamos assim, qualquer forma de empirismo ou empatia. Nas palavras de Freitas (2010, p. 95),

A associação entre avaliação e poder do professor (e da escola) joga muitas das propostas "inovadoras" da avaliação em um terreno dicotômico: formas autoritárias versus formas democráticas de avaliar. Entretanto, a solução para as questões de avaliação são podem ser pautadas como um dilema entre o autoritarismo e o democratismo. Há nos processos avaliativos uma contradição e não um dilema. Na verdade, o antagonismo entre professor e aluno, potencializado pela questão da avaliação, está definido pelos objetivos educacionais da escola, ao colocar o aluno em uma posição de subordinação e ao isolar a escola da vida e de seus motivadores naturais. Para a resolução plena desta questão, a forma escolar deveria devolver esta relação (entre professor e aluno) ao seu leito natural, ou seja, uma relação que fosse baseada na maior experiência e conhecimento do professor, reconhecida pelo aluno, ao invés, de baseada na autoridade do professor. Mas isto esbarra com os objetivos da escola capitalista como já vimos. Há que se concluir, também, por esta mesma via, que a questão da avaliação não se resolve pelo dilema: formas classificatórias de avaliar versus formas não classificatórias baseadas em pareceres, conceitos e que tais. Aqui também a mudança esconde uma relação bem mais complexa

Enfim, diante do exposto até aqui e buscando a radicalidade na análise, retomamos a experiência da escola Iraci no que tange a avaliação escolar, antes, porém, elucidamos que no exercício da prática, a contradição é um elemento fundante.

Diante das afirmações feitas até aqui e das leituras dos documentos legais da escola, sobretudo do PPP (2009), a avaliação passa a ser constitutiva de uma nova prática social, com relações harmônicas, na quais a solidariedade e a justiça são as bases de edificações de outro tempo, lê-se no PPP (2009, p. 36),

Propomos, portanto, a superação da nota e da classificação. Nos Ciclos de Formação Humana a avaliação assume como papel central o constante perguntar-se, problematizar-se ao coletivo de educadores do ciclo e do conjunto da escola. Por isso, ela assume o caráter permanente, dialógico, articulado e contínuo, com retomadas constantes, relacionando os conhecimentos trabalhados com o horizonte e com a perspectiva dos conhecimentos que precisam ser apropriados pelo coletivo de educandos e pelo sujeito envolvido.

Nessa perspectiva, a avaliação deixa de ser responsabilidade individual e passa a ser assumida pelo coletivo da escola, que por sua vez, tem o compromisso, que, em posse dos dados, deve fazer intervenções para superar limites e cumprir os objetivos elencados para cada ciclo.

Para além das funções curriculares a avaliação abrange todas as práticas e sujeitos envolvidos na ação de ensino-aprendizagem. No processo de avaliação estão imbricadas as ações necessárias à formação humana, portanto, as relações vividas no interior da escola precisam ser constantemente avaliadas. Para isso, são construídos espaços e tempos específicos para avaliar, desde os conselhos de classes participativos, as instâncias como o grêmio estudantil, conselho escolar e associação de pais e mestres. 
Retornaremos à questão anunciada aqui num momento mais especifico desse trabalho. Cabe, por ora, a clareza de que não são os processos de avaliações por si só que determinam as práticas de exclusão e de acomodação nas escolas de massas, há uma forma escolar que incorpora mecanismo de domínio interno, entre esses, está à avaliação. Portanto, construir a escola para a classe trabalhadora implica, segundo os estudos do Freitas (2010, p. 96)

Se queremos uma nova forma de avaliação, será necessário repensar a escola que queremos a partir de novas funções sociais, as quais necessariamente conflitarão com os objetivos do atual sistema social. Isso coloca para a educação outros objetivos e requer outra forma escolar com repercussões para as formas de avaliação. Estas novas funções podem ser formuladas colocando-nos na ótica das classes que desejam transformar a atual sociedade e que, por tanto, necessitam se auto-organizar para isso, conhecer a realidade e dominar o conteúdo das ciências. Sobre este tripé, pode-se pensar qual seria a nova forma desejada para uma escola compromissada com tais funções.

A possibilidade de intervenção político-pedagógica se dá mediante as escolhas que respeitem os processos humanos, uma vez que estes estão envoltos num contexto social. Há, entretanto, que se considerar as influências sobre os determinantes que obstante controlam os diferentes papéis nessa sociedade. Isso não significa deixar cada sujeito a mercê do que as condições individuais/naturais os possibilitam, reiteramos que somos humanos necessariamente porque ultrapassamos os limites que a natureza nos impõe. (KLEIN, 2002; VYGOTSKY, 2005).

\section{OS CICLOS DE FORMAÇÃO HUMANA NO COLÉGIO IRACI}

Desde sua constituição (1998) e autorização (1999) como escola pública, o coletivo do Colégio Estadual do Campo Iraci Salete Strozak elaborou três Projetos Político Pedagógico, nos anos de 2000, de 2002 e de 2009. Dentre os contrapontos elencados nos projetos educativos dessa escola classificam-no como um projeto 'híbrido' (JANATA, 2012), ou seja, ao mesmo tempo em que se propõem a ser coerente com a pedagogia do MST, precisa assumir a lógica estabelecida para escola pública paranaense e também pela 'bricolagem' (MAINARDES, 2007), na medida em que busca em experiência consolidadas, constituir seu próprio jeito de ser escola.

A opção pelos Ciclos de Formação Humana teve uma construção de aproximadamente cinco anos (2005- 2009), se considerarmos sua aprovação em 2010 pelo Parecer 117/10 de 11 de fevereiro de 2010 do Conselho Estadual de Educação (CEE-PR) e pela Resolução 3922/10 da SEED-PR que aprovam e autorizam sua implementação, como experiência pedagógica, por cinco anos. Novamente chama a atenção o processo de luta empreendido para a aprovação do PPP, fato ímpar no Estado, uma vez que a própria legislação nacional (LDB, 1996) garante que a comunidade escolar define seu projeto educativo.

Destacamos que o ciclo compreende um amplo conceito, o qual fomos detalhando ao longo do texto. O PPP vai dando indicativos de como se organiza cada ciclo, possibilitando clareza aos docentes e aos executores das políticas, tomando-se o cuidado de não descumprir as orientações da secretaria de educação do Estado. Isso se percebe na preocupação de citar-se as leis e as diretrizes, entre outras.

O quadro abaixo possibilita a visualização da organização dos ciclos na escola e detalha o escrito acima: 
Tabela 2: Organização da Educação Básica no Colégio Estadual do Campo Iraci Salete Strozak.

\begin{tabular}{|c|c|c|c|}
\hline CICLOS DA VIDA HUMANA & $\begin{array}{c}\text { CICLO DA } \\
\text { FORMAÇÃ̃O } \\
\text { HUMANA }\end{array}$ & $\begin{array}{c}\text { CICLO DA EDUCAÇÃO } \\
\text { BÁSICA }\end{array}$ & IDADE \\
\hline \multirow{3}{*}{ INFÂNCIA } & $\begin{array}{c}\text { I Ciclo da Formação } \\
\text { Humana }\end{array}$ & $\begin{array}{c}\text { Ciclo único - Educação } \\
\text { Infantil }\end{array}$ & $\begin{array}{l}4 \text { anos } \\
5 \text { anos }\end{array}$ \\
\hline & $\begin{array}{l}\text { II Ciclo da Formação } \\
\text { Humana }\end{array}$ & $\begin{array}{l}\text { I Ciclo do Ensino } \\
\text { Fundamental }\end{array}$ & $\begin{array}{l}6 \text { anos } \\
7 \text { anos } \\
8 \text { anos }\end{array}$ \\
\hline & \multicolumn{3}{|c|}{ Classe Intermediária } \\
\hline \multirow[t]{2}{*}{$\begin{array}{c}\text { PRÉ- } \\
\text { ADOLESCÊNCIA }\end{array}$} & $\begin{array}{c}\text { III Ciclo da Formação } \\
\text { Humana }\end{array}$ & II Ciclo do Ensino Fund. & $\begin{array}{c}9 \text { anos } \\
10 \text { anos } \\
11 \text { anos }\end{array}$ \\
\hline & \multicolumn{3}{|c|}{ Classe Intermediária } \\
\hline \multirow[t]{2}{*}{ ADOLESCÊNCIA } & $\begin{array}{c}\text { IV Ciclo da Formação } \\
\text { Humana }\end{array}$ & III Ciclo do Ensino Fund. & $\begin{array}{l}12 \text { anos } \\
13 \text { anos } \\
14 \text { anos }\end{array}$ \\
\hline & \multicolumn{3}{|c|}{ Classe Intermediária } \\
\hline JUVENTUDE & $\begin{array}{c}\text { V Ciclo da Formação } \\
\text { Humana }\end{array}$ & Ciclo único - Ensino Médio & $\begin{array}{l}15 \text { anos } \\
16 \text { anos } \\
17 \text { anos }\end{array}$ \\
\hline
\end{tabular}

Conforme exposto na tabela, a educação básica está divida em cinco ciclos, sendo um único ciclo na educação infantil e no ensino médio e três no ensino fundamental. Cada ciclo é composto de até três anos de duração. Aqui se apresenta um dos limites da implementação, pois muitos professores não conseguem romper com a relação anual, característica do regime seriado. Para que de fato o trabalho fosse concretizado com êxito anunciado no projeto e nos documentos orientadores os docentes precisariam entender que os estudantes têm mais tempo para aprendizagem e que se não conseguiram alcançar os objetivos, estes deverão ser retomados no próximo ano do ciclo.

Além da ampliação do tempo, os agrupamentos (turmas) observam o desenvolvimento humano, o ciclo da vida, a partir de uma idade referência. Apesar de não estar explicito no PPP (2009) a fundamentação teórica nos leva a concluir que a temporalidade descrita como: infância, pré-adolescência, adolescência e juventude cumprem apenas um aspecto formal, interessando de fato o desenvolvimento e a maturidade em que cada sujeito se encontra.

A escola faz a opção de romper com as turmas homogêneas, que apresentam o mesmo nível de conhecimento avaliado pela escola, assim são as avaliações de conteúdo, apenas, não são suficientes para dizer se o estudante vai para aquela turma ou não. Novamente a referência da seriação tem impedido os avanços nesse aspecto, acostumados a reprovar os estudantes que não conseguem atingir o que foi estabelecido para o grupo, os professores se sentem frustrados por aquilo que consideram 'passar sem saber'.

Outro elemento que tem gerado conflitos e avanços é a avaliação, pois a escola trabalha com instrumentos específicos que divergem das demais escolas onde prevalecem as notas. Na escola Iraci constitui-se formas de registros e avaliações, as Pastas de Acompanhamento; o Caderno de Registro das Avaliações e os Pareceres Descritivos. Além disso, a escola tem um instrumento de avaliação interna, que são os Simulados e os Conselhos de Classe Participativos, que partem da compreensão de todos tem o direito de avaliar e não apenas os professores. 
Essas têm sido uma das principais problemáticas identificadas e já relatada nas demais experiências de escolas cicladas. A formação de coletivos dos ciclos, embora esteja previsto no PPP (2009), não se efetiva pelas razões já escritas ${ }^{4}$. As formações continuadas são feitas parcialmente, na medida em que os professores conseguem se organizar para estarem presentes. Assim, o trabalho é realizado de forma precarizada, sem a qualidade e o empenho que o projeto exige. A citação abaixo demonstra a intenção da escola em efetivar o processo coletivo, mas que de fato não se concretiza pela forma como são feitas as contratações e lotações dos professores, neste Estado.

O processo pedagógico é coletivo e assim precisa ser conduzido, enraizando-se junto à comunidade tornando-se forte. A organização dos coletivos de educadores ocorre em três níveis: coletivo de educadores da escola, coletivo de educadores de um curso (infantil, fundamental...) e coletivo de educadores do ciclo. Coletivo de educadores do ciclo: reúnese semanal, quinzenal e/ou mensalmente para formação, para a realização da hora atividade, juntamente com a coordenação da escola, realizando avaliações, estudos e planejamento (PPP, 2009, p. 56).

Essa fragilidade, apresentada na concretização da proposta na escola Iraci, aparece nos trabalhos de Mainardes (2007) e Neves (2005), ambos demonstram nas pesquisas as descrenças dos professores na efetivação política e a dificuldade de implantá-la na sala de aula.

Embora haja um esforço da equipe de referência (diretiva) em inserir a cada ano o novo grupo, tem enfrentado o desconhecimento e a resistência, especialmente daqueles que chegam pela primeira vez à escola, que caracterizam o processo como uma imposição da gestão, "feita de cima para baixo" e preferem se calar e não provocar atritos, porém reproduzem as velhas práticas, no interior de suas salas de aulas.

Apesar dos limites apresentados, os avanços são perceptíveis, especialmente no que se refere a auto-organização dos estudantes, sobretudo pautado no processo pedagógico coletivo, decido por todos para isto desde a mais tenra idade. Segundo o projeto político pedagógico Iraci Salete (PPP, 2009) apoiado em estudos de Pistrak,

Esta organização precisa ser construída processualmente com educandos e educandos, logo, não poderia vir em pacote pronto, isso não seria educativo junto ao coletivo de estudantes. Por outro lado não precisamos dar inicio a caminhada, não podemos ser ingênuos, achando que a organização acontece por si só. (MST, 2008, p. 38)

A auto-organização na escola é a forma de garantir, minimamente, o protagonismo dos sujeitos na escola, mesmo entre aqueles que se arriscam e acabam correndo o risco de ser repreendido, rechaçados pelos docentes e colegas, há um amadurecimento e tomada de consciência diferente dos que se negam a participar.

Os Ciclos vêm se apresentando como possibilidades de debater além da lógica linear e devem ser compreendidos como articuladores do dinâmico e complexo processo de desenvolvimento e de aprendizagem dos sujeitos. Não podem apenas legitimar a mudança da realidade formal escolar, mas também oferecer a possibilidade de superá-la em todas as suas configurações de ensino conhecidas, como, por exemplo, o próprio processo de avaliação que é previsto muitas vezes pelas desigualdades no desenvolvimento e na aprendizagem entre os sujeitos. Sabemos que, dessa forma, ainda estamos estagnados 
naquela conservadora natureza de transferir nos sujeitos os conteúdos hierarquicamente organizados.

Esse novo modo de pensar exige definição de princípios, metas, conhecimentos próprios, de acordo com as idades, principalmente aos grupos de idade-ciclo. Se estivermos numa lógica de seriação podemos enquadrar o processo de ensino em sequências anuais, semestrais ou ainda, bimestrais. Contrariamente ao que ocorre nos Ciclos, os tempos têm outra dinâmica, mais extensa e ressignificada a partir das temporalidades ou da condição humana do interagir sócio-antropológico (os tempos da vida). Os ciclos da vida são processuais, pois não cessam na prescrição ou no conceito final sobre as vivências conquistadas.

Assim na escola do ciclo o tempo de aprendizagem é maior, pois a infância compreende mais que um ano, compreende como se aprende em cada ciclo da vida passa a ser central, outros espaços também são considerados educativos e a sala de aula perde sua centralidade, embora seja um espaço importante, compreende-se a biblioteca, os laboratórios, a comunidade, as famílias como locais educativos. A educação passa a incorporar novos elementos para ensinar e aprender.

Dentre os elementos trazidos no debate deste texto e olhando para a recente experiência do Colégio Estadual Iraci Salete Strozak precisamos considerar que nas condições reais da sociedade capitalista mexer na estrutura é um elemento importante, a opção curricular em ciclos vem representando em diferentes tentativas e, também, neste colégio a forma escolhida para se contrapor a lógica formal e fazer a luta por uma outra sociedade.

Enfim, ao propor a organização em Ciclos de Formação Humana, a escola vem tentando colocar a ação educativa da escola em movimento. Ciclo é movimento, não nos deixa parados, é processo, é relação, é agrupar e reagrupar-se para aprender e ensinar (PPP, 2009).

A experiência relatada acima reafirma a importância do debate sobre a gestão da escola pública, desde quem as define e como são executadas. O Ciclo de Formação Humana é a forma que os Sem Terra encontram para colocar em prática os princípios filosóficos e pedagógicos construídos na luta deste povo, buscando romper com a lógica reducionista, presente na proposta destinada às escolas até então. Apesar de todos os avanços propostos, a efetivação é comprometida pela falta de compromisso dos órgãos executores que não garantem as condições necessárias, ou ainda, uma leitura mais apurada nos revelaria que este projeto ameaça a estrutura capitalista, reafirmada mesmo que de forma velada pela política educativa estadual.

\section{CONSIDERAÇÕES FINAIS}

A escola Iraci traz, como perspectiva, a transformação social, a partir da formação humana onmilateral. Todos os documentos, referenciais apontam para isso. Ao se propor a desenvolver essa perspectiva, estando imersa no sistema capitalista, vai tecendo formas a partir da organização dos Ciclos de Formação Humana.

Verificamos, nesse processo, limites que se colocam, especialmente por ser uma escola pública, refém das decisões centralizadas do governo. Nesse sentido assentam-se as questões que decorrem de fatores externos à escola, que envolvem diretamente as decisões no campo das políticas educacionais, destacando-se a contratação dos professores. A tendência de homogeneização da organização pedagógica das escolas da rede estadual, não possibilita aos professores ter mais tempo na escola, nem a participarem das formações continuadas e se aprofundarem no conhecimento do projeto educativo da escola. 
Apesar dos Ciclos de Formação Humana possibilitarem uma nova compreensão e organização do tempo escolar, da metodologia e da avaliação, a referência de grande parte dos docentes é o regime seriado.

A formação humana plena presume contemplar a educação intelectual, física e tecnológica. Apesar destes aspectos estarem contemplados nos objetivos educativos da escola, se concretizam com muitos limites e fragilidades pois, o ensino é extremamente marcado pelo reducionismo, e pelo currículo fragmentado e sem nexos com as contradições sociais. Prevalece a prática da memorização em detrimento da construção dos conceitos, apontados pelos teóricos aqui estudados, como basilar para formação humana pretendida pela escola.

Por outro lado, a escola é o espaço de socialização dos adolescentes e jovens, "ponto de encontro, uma vez que residem longe [...] é onde encontram amigos, paqueras e para fugir do trabalho" (LEINEKER, 2012). E também onde aprendem sobre o lugar em que vivem, encontram espaço para o lazer e o uso de tecnologias, com práticas que exigem pensar sobre si e os outros.

A "arquitetura escolar", radicada com tempos e formatos individualistas e parciais, não tem possibilitado avançar em todos os aspectos que a escola se propõe. Em nossa análise não identificamos problemas na fundamentação teórica, mas sim na concretização da prática, que excede as próprias condições e vontades do coletivo escolar.

Constatar que a escola Iraci apresenta a vivência de um caminho entrelaçado à lutas pela terra, leva-nos a evidenciar elementos presentes em profissionais e na comunidade atendida, que configuram uma visão crítica dos processos histórico sociais, de reivindicação de direitos, iniciativa e de posições políticas que possibilitam um revisão consciente e qualificada da proposta que defendem. Isso fez com que a escola protagonizasse, na rede escolar estadual, uma proposta contrária a própria lógica da política, e única em todo o Estado. Isso se constitui um grande avanço se considerarmos as ações hegemônicas e centralizadas.

O desafio sugere seguir na luta, pois criar experiências de outras formas educativas, comprometidas com a classe trabalhadora é crucial para o avanço da própria classe.

Os Ciclos de Formação Humana são determinantes em todo esse processo, além da retórica progressista, a escola Iraci se vincula aos princípios pedagógicos do MST, o que os torna conectados às demandas da realidade concreta, em direção à emancipação humana, que só será plena, quando livres da alienação, os seres humanos puderem usufruir das produções humanas.

\section{Referências}

ALAVARSE, Ocimar Munhoz. A organização do ensino fundamental em ciclos: algumas questões. Revista Brasileira de Educação. São Paulo. v. 14, n.40, jan/abr.2009.

CUNHA, Emmanuel R. Os ciclos de formação - a reorganização da escola fundamental brasileira e o trabalho pedagógico dos professores. Disponível in www.nead.unama.br/site/bibdigital/pdf/artigos_revistas/20.pdf. Acesso março de 2012.

DUARTE, Newton. A anatomia do homem é a chave da anatomia do macaco: a dialética em Vigotski e em Marx e a questão do saber na educação escolar. Educação \& Sociedade, ano XXI, no 71 , julho de 2000.

FETZNER, Andréa Rosana. A implantação dos ciclos de formação em Porto Alegre: para além de uma discussão do tempo-espaço escolar. Revista Brasileira de Educação v. 14 n. 40 jan./abr. 2009 
FREITAS, Luiz C. Ciclos, Seriação e avaliação: confrontos de lógicas. São Paulo: Moderna, 2003.

Materialismo Histórico Dialético: pontos e contra pontos. In: Cadernos do ITERRA, Ano VII, Nº14, II Seminário Nacional O MST e a Pesquisa. Novembro, 2007. . Avaliação: para além da "forma escola". Educação: teoria e prática, v. 20. no.35, Rio Claro, SP, jul/dez 2010.

HAMMEL, Ana Cristina. Ciclos de formação humana no Colégio Estadual do Campo Iraci Salete Strozak. Dissertação de Mestrado. Universidade Estadual do Oeste do Paraná, Cascavel. 2013.

JUNIOR, C. Prado. Teoria marxista do conhecimento e método dialético materialista. In. http://www.ebooksbrasil.org/eLibris/caio.html. acesso em 12 de agosto de 2012.

KLEIN, L. Regina. Alfabetização: quem tem medo de ensinar? 4. ed. São Paulo: Cortez; Campo Grande: Editora da Universidade federal de Mato Grosso do Sul , 2002.

KOSIK, Karel. Dialética da totalidade concreta. In:

A dialética do concreto. $5^{\text {a }}$ ed. Rio de Janeiro: Paz e Terra, 1989.

KOSTIUK. G.S. Alguns aspectos da relação recíproca entre educação e desenvolvimento da personalidade. In. VYGOTSKY, L. LEONTIEV, A. LURIA. Psicologia e Pedagogia: bases psicológicas da aprendizagem e do desenvolvimento. São Paulo: Centauro, 2005.

KRUG, Andréa Rosana. Ciclos de formação: uma proposta transformadora. 3ed. Porto Alegre: Editora Mediação, 2006.

Ciclos de formação: desafios da teoria pedagógica para as

$\begin{array}{lll}\text { práticas escolares. } & \text { UFRGS/UFF. } & \text { Disponível }\end{array}$

www.anped.org.br/reunioes/28/textos/gt06/gt06524int.rtf. Acesso nov. 2012.

ITERRA - Instituto Técnico de Capacitação e Pesquisa da Reforma Agrária. Dossiê MST Escola: documentos e estudos 1990-2001. Veranópolis - RS: ITERRA, 2005.

JANATA, Natacha E. Juventude que ousa lutar: trabalho, educação e militância dos jovens de assentados do MST. Tese de Doutorado. Universidade Federal de Santa Catarina, Florianópolis, 2012.

LEONTIEV, Aléxis. O desenvolvimento do psiquismo. Lisboa, Livros Horizontes, 1978.

LEINERKER, Mariulce. S.L. Escolas do campo no Paraná: entre a conquista e a imposição. Dissertação de Mestrado. Universidade Federal do Paraná, Curitiba-PR, 2012.

MAINARDES, Jefferson. Reinterpretando os Ciclos de aprendizagem. São Paulo: Cortez, 2007.

Escola em ciclos: fundamentos e debates. São Paulo: Cortez, 2009.

; STREMEL, Silvana. A organização da escolaridade em ciclos:

aspectos de sua emergência, desenvolvimento e discussões atuais. Acta Scientiarum. Education Maringá, v. 33, n. 2, p. 227-238, 201. Disponível em: periodicos.uem.br/ojs/index.php/ActaSciEduc/article/.../12647/pdf. Acesso em Nov. 2012.

MANACORDA, Mario A. Marx e a pedagogia Moderna. São Paulo: Autores Associados, 1991.

MARTINS, Lígia Márcia. Da formação Humana em Marx à Crítica da Pedagogia das Competências. In: DUARTE, Newton (Org). Crítica ao Fetichismo da Individualidade. Campinas: Autores Associados, 2004.

MARTINS, Fernando J. Ocupação da Escola: uma categoria em construção. Tese de Doutorado. Universidade Federal do Rio Grande do Sul. Porto Alegre, 2009.

MARTINS, Miguel Gomes. Progressão continuada e trabalho docente. Dissertação de Mestrado. Universidade de Sorocaba. Sorocaba/SP, 2007.

MÉSZAROS, Istevan. Educação para além do capital. São Paulo: Boitempo, 2005. 
MIRANDA, Marília G. Sobre tempo e espaços da escola: do princípio do conhecimento ao princípio da sociedade. Educ. Soc., Campinas, vol. 26, n. 91, p. 639-651, Maio/Ago. 2005. Disponível em <http://www.cedes.unicamp.br> Acesso Nov. 2012.

MOVIMENTO DOS TRABALHADORES RURAIS SEM TERRA. (MST). Objetivos formativos, s/d.

NEVES. Simone do R. Pereira. A escola organizada em ciclos: o processo historio de sua implantação na rede municipal da cidade de Ponta Grossa - Paraná, no período de 20012004. Dissertação de Mestrado. Universidade Estadual de Ponta Grossa-UEPG, 2005.

PARENTE, C. M. Darós. A construção dos tempos escolares. Educação em Revista, Belo Horizonte, v.26. nº2, ago. 2010.

PISTRAK, M. Fundamentos da escola do trabalho. São Paulo: Expressão Popular, 2000.

PROJETO POLÍTICO PEDAGÓGICO DO COLÉGIO ESTADUAL IRACI SALETE STROZAK. PPP. Rio Bonito do Iguaçu, 2009.

PROJETO POLÍTICO PEDAGÓGICO DO COLÉGIO ESTADUAL IRACI SALETE STROZAK. PPP. Rio Bonito do Iguaçu, 2000.

ROSSLER, João H. A educação como aliada da luta revolucionária pela superação da sociedade alienada. In: DUARTE, Newton (Org). Crítica ao Fetichismo da Individualidade. Campinas: Autores Associados, 2004.

PARANÁ. Secretaria de Estado da Educação do Paraná, SEED-PR Resolução no 614/2004 de 17/02/2004.

SOUZA. R.F. Tempos de infância, tempos de escola: a ordenação do tempo escolar no ensino público paulista (1892-1933). Educação e Pesquisa, São Paulo, v. 25, n. 2, p. 127 143, jul./dez. 1999.

TEXEIRA, Edival. Ciclos de aprendizagem: trajetórias e fundamentos. Curitiba/PR: editora UTFPR, 2008.

VYGOTSKY, L. LEONTIEV, A. LURIA. Psicologia e Pedagogia: bases psicológicas da aprendizagem e do desenvolvimento. São Paulo: Centauro, 2005.

. A construção do Pensamento e da Linguagem. São Paulo: Martins Fontes,

2000.

Notas:

${ }^{1}$ Mestre em educação pela pela Universidade Estadual do Oeste do Paraná- UNIOESTE e docente da Universidade Federal da Fronteira Sul. E-mail: hammel.anacristina@gmail.com.

2 Doutora em educação e docente da Universidade Estadual do Oeste do Paraná -UNIOESTE. E-mail: liliamfpb@gmail.com

${ }^{3}$ Os grifos têm como objetivo dar destaque as níveis de desenvolvimento que o autor trabalha e que também se fazem presente no PPP (2009) da escola Iraci.

${ }^{4}$ Elencamos, como elementos que impedem a formação dos coletivos, o pouco tempo de permanência na escola, a precarização dos contratos, que gera instabilidade, insegurança e falta de compromisso, pois não sabem se irão permanecer no colégio e ainda o excesso de trabalho ocasionado pelo grande número de escolas, nas quais os professores precisam ser lotados para fechar a carga horária, de 40 (quarenta) aulas semanais, sendo que dessas apenas 6 (seis) aulas atividades, destinadas a preparar o trabalho, fazer as correções e demais práticas que o trabalho pedagógico exige. 